\title{
PENGARUH METODE MIND MAPPING TERHADAP PENGUASAAN KONSEP DAN HABITS OF MIND PADA MATERI SISTEM EKSRESI MANUSIA
}

\author{
Marta Dinata $^{1)}$, Prasetyo Arum Mulyo ${ }^{2)}$ \\ ${ }^{12)}$ Pendidikan Biologi FKIP Universitas Lancang Kuning \\ email ${ }^{1)}$ :martadinata@unilak.ac.id \\ email $^{2)}$ :prasetyo.arm@gmail.com
}

\begin{abstract}
ABSTRAK: Penelitian ini bertujuan untuk mengetahui pengaruh metode mind mapping terhadap penguasaan konsep dan habits of mind siswa pada materi sistem eksresi manusia. Pengumpulan data dilakukan melalui pretest, posttest dan lembar observasi. Teknik analisis data dalam penelitian ini berupa t-test. Rerata $N$-gain kelas eksperimen 0.56 (sedang) sedangkan kelas kontrol 0.31 (sedang). Dari hasil uji-t terdapat perbedaan yang signifikan antara kelas kontrol dan eksperimen. Rerata aktifitas siswa kelas eksperimen pertemuan I 90,38\% II 96,15\% dan kelas kontrol pertemuan I 58,65\% II 74,03\%. Rerata aktifitas guru kelas eksperimen dan kotrol pertemuan I 100\% II 100\%. Dengan demikian dapat disimpulkan bahwa penggunaan metode mind mapping berpengaruh terhadap penguasaan konsep siswa pada materi sistem eksresi manusia

Kata Kunci: Metode Mind Mapping, Habits of Mind, Sistem Eksresi Manusia
\end{abstract}

\begin{abstract}
This study aims to determine the effect of mind mapping methods on mastery of concepts and habits of mind of students in human excretion system material. Data collection was done through pretest, posttest and observation sheet. The data analysis technique in this study is a t-test. The average $N$-gain of the experimental class is 0.56 (medium) while the control class is 0.31 (medium). From the results of the t-test there are significant differences between the control class and the experiment. The average activity of the experimental class I students $90.38 \%$ II $96.15 \%$ and the control class I meeting $58.65 \%$ II $74.03 \%$. The average activity of the experimental class teacher and the 100\% II 100\% II meeting control meeting. Thus it can be concluded that the use of mind mapping method affects the mastery of students' concepts in human excretion system material Keywords: mind mapping method, habits of mind,human excretion system.
\end{abstract}




\section{PENDAHULUAN}

Pendidikan merupakan bagian integral dalam pembangunan. Proses pendidikan tidak dapat dipisahkan dari proses pembangunan itu sendiri. Pembangunan diarahkan dan bertujuan untuk mengembangkan sumber daya manusia yang berkualitas dan pembangunan sektor ekonomi, yang satu dengan yang lainnya saling berkaitan dan berlangsung dengan bersamaan (Hamalik, 2009).

Untuk mencapai tujuan pendidikan nasional berbagai cara yang harus dilakukan melalui peningkatan kompetensi pendidik dan tenaga kependidikan lainnya. Pendidik diberikan kesempatan untuk mengembangkan diri untuk menyelesaikan masalah pendidikan dan pembelajaran melalui pengembangan yang inovatif, terencana dan dilaksanakan secara terkendali. Pada saat ini banyak usaha yang telah dilakukan untuk mencapai tujuan pendidikan nasional salah satunya mengembangkan model pembelajaran PAIKEM (Pembelajaran yang aktif , inovatif, kreatif, efektif dan menyenangkan) (Ratnasari, 2010).

Proses pembelajaran akan lebih efektif apabila siswa lebih aktif berpartisipasi dalam proses pembelajaran. Melalui partisipasi seorang siswa akan dapat memahami pelajaran dari pengalamannya

sehingga akan mempertinggi hasil belajarnya menurut (Dimyati \& Mudjiono, 2002).
Biologi merupakan salah satu pelajaran yang sangat penting dan berhubungan dengan kehidupan seharihari. Proses pembelajaran biologi adalah proses yang menyeluruh dan saling berhubungan antara materi biologi yang satu dengan lainnya. Konsep awal yang diterima siswa menjadi syarat untuk penguasaan konsep berikutnya. Pengetahuan awal siswa pada setiap pengalaman belajarnya akan berpengaruh terhadap bagaimana mereka belajar dan apa yang dipelajari selanjutnya. Dengan demikian diperlukan model dan metode penyampaian materi yang tepat, yang dapat memberdayakan siswa baik dari segi akademik, kecakapan sosial, dapat memecahkan masalah dengan sifat terbuka dalam suatu pembelajaran yang lebih tepat dan menarik, sehingga tujuan pendidikan yang sesuai kurikulum pendidikan dapat tercapai (Trianto, 2012).

Mind mapping adalah sebuah metode untuk mengelola informasi secara keseluruhan melalui pemetaan peta pikiran berbetuk percabangan yang dituangkan langsung kedalam media tulis (baik kertas maupun digital). Mind mapping pada umumnya berupa suatu percabangan bagan-bagan. Manfaat dari metode pencatatan menggunakan mind 
mapping tesebut diantaranya adalah untuk mempermudah proses pengingatan, mempercepat proses pencatatan karena hanya menggunakan kata kunci, mudahnya kita mengingat suatu informasi utama karena tema utama terdefinisi dengan jelas di tengah

( Buzan, 2006)

Beberapa penelitan tentang habits of mind, Penelitian Sriyati (2011) menunjukkan bahwa asesmen formatif dapat meningkatkan habits of mind mahasiswa, meningkatkan hasil belajar, membentuk karakter yang lebih baik dan menimbulkan kepedulian mahasiswa terhadap keanekaragaman hayati Indonesia. Steinkuehler \& Duncan (2008) melakukan penelitian yang berjudul "Scientific Habits of Mind in Virtual Worlds" melalui pembelajaran berbasis permainan secara informal, menyimpulkan permainan berpotensi untuk mengembangkan scientific habits of mind. Berdasarkan penelitian-penelitian tersebut, terlihat bahwa sesungguhnya siswa sudah mempunyai habits of mind sebagai potensi dalam dirinya dan kemampuan habits of mind dapat meningkatkan pengetahuan dan keterampilan siswa.

\section{METODE PENELITIAN}

Penelitian ini merupakan penelitian kuasi eksperimen dengan menggunakan Control Group Pretest Posttest Design (Mc. Millan \& Schumacher, 2001). yang terdiri dari 4 kelas parallel yaitu kelas VIII.1,VIII.2, VIII.3, VIII.4. Sebagai sampel diambil 2 kelas dengan menggunakan teknik sample random sampling, sampel yang terpilih yaitu kelas VIII.1 sebagai kelas kontrol dengan jumlah 26 siswa dan kelas VIII.2 kelas eksperimen dengan jumlah 26 siswa.

Analisis penelitian dilakukan secara kuantitatif untuk mengetahui besarnya peningkatan hasil belajar siswa pada materi sistem eksresi manusia pada siswa kelas VIII SMP Negeri 33 Pekanbaru. Data hasil pretest dan posttest, dianalisis untuk melihat peningkatan hasil belajar siswa.

Lebih jelas lihat Tabel 1.

Tabel 1. Rancangan Control Group Pretest Posstest Design

\begin{tabular}{|c|c|c|c|}
\hline Kelas & Pretest & $\begin{array}{c}\text { Treat } \\
\text { ment }\end{array}$ & Posttest \\
\hline Eksperimen & $\mathrm{O}_{1}$ & $\mathrm{X}_{1}$ & $\mathrm{O}_{2}$ \\
\hline Kontrol & $\mathrm{O}_{1}$ & $\mathrm{X}_{2}$ & $\mathrm{O}_{2}$ \\
\hline
\end{tabular}

Sumber : (Mc. Millan \& Schumacher, 2001)

Keterangan :

$\mathrm{X}_{1}$ : Pembelajaran dengan Metode Mind Mapping and Habits of mind

$\mathrm{X}_{2}$ : Pembelajaran konvensional

$\mathrm{O}_{1} \quad$ : Pretest (Sebelum proses pembelajaran)

$\mathrm{O}_{2} \quad$ : Posttest (Setelah proses pembelajaran)

Identifikasi menggunakan teknik sample random sampling yang diperoleh dari 
analisis kemudian dihitung persentase siswa berdasarkan kategori perolehan skor N-Gain, dengan berpedoman pada Tabel 2 .

Tabel 2 : Kategori Perolehan Skor N-Gain

\begin{tabular}{|c|c|}
\hline Batasan & Kategori \\
\hline $\mathrm{g}>0,7$ & Tinggi \\
\hline $\begin{array}{c}0,3<\mathrm{g} \\
\leq 0,7\end{array}$ & Sedang \\
\hline $\mathrm{g} \leq 0,3$ & Rendah \\
\hline
\end{tabular}

(Sumber : Meltzer, 2002)

Selanjutnya Uji normalitas diperlukan untuk mengetahui distribusi data. Normalitas data diketahui melalui sebaran regresi yang merata disetiap nilai. Salah satau metode yang digunakan untuk menguji normalitas data adalah uji Kolgomorov Smirnov (KS-21). Rumus Kolgomorov Smirnov adalah:

\section{Tabel 3 : Uji Normalitas}

$$
K S=\left|F n_{(\mathrm{Yi}-1)}-F o_{(\mathrm{Yi})}\right|
$$

(Sumber : Wulandari, 2010)

Keterangan :

$$
\begin{array}{ll}
\text { KS } & \text { : Nilai } \mathrm{KS}_{\text {hitung }} \\
\text { Fn(Yi-1) } & \begin{array}{l}
\text { Frekuensi persentase } \\
\text { kumulatif pada waktu } \\
\text { sebelum i }
\end{array} \\
& \text { F0(Yi) } \quad \text { Frekuensi data sebaran } \\
& \text { normal pada saat } \mathrm{i}
\end{array}
$$

Pengujian homogenitas dilakukan untuk mengetahui keseragaman data. Dalam analisis regresi, data penelitian yang baik harus mempunyai sebaran data yang homogen dan metode yang digunakan untuk mengujinya adalah uji levene (levene test). Rumus levene test adalah :

Tabel 4 : Uji Homogenitas

$$
W=\frac{(n-k)}{(k-1)} \frac{\sum_{i=1}^{k} n_{i}\left(\bar{Z}_{i .}-\bar{Z}\right)^{2}}{\sum_{i=1}^{k} \sum_{j=1}^{n_{i}}\left(Z_{i j}-\bar{Z}_{i .}\right)^{2}}
$$

(Sumber : Wulandari, 2010)

Keterangan :

$n=$ jumlah observasi

$k$ = banyaknya kelompok

$Z_{i j}=\left|Y_{\mathrm{ij}}-\bar{Y}_{\mathrm{i}}\right|$

$\bar{Y}_{i}=$ rata - rata dari kelompok ke i

$\hat{Z}_{i . .,}=$ rata - rata kelompok dari $\mathrm{Z}_{\mathrm{i}}$

$\hat{Z}$. . = rata - rata menyeluruh (overall mean) dari $\mathrm{Z}_{\mathrm{ij}}$

Tolak H0 jika W > F $(\alpha ; \mathrm{K}-1, \mathrm{n}-\mathrm{k})$

\section{HASIL DAN PEMBAHASAN}

Berdasarkan uji $\mathrm{t}$ data pretest diperoleh nilai Sig. (2-tailed) untuk kelas kontrol dan eksperimen keputusan terima $\mathrm{H} 0$ yang artinya tidak terdapat perbedaan antara pretest kelas kontrol dan pretest kelas eksperimen. Hal ini menunjukan bahwa siswa pada kelas kontrol dan kelas eksperimen mempunyai pengetahuan awal yang sama pada materi sistem ekskresi.

Berdasarkan hasil uji-t dimana nilai Sig. (2-tailed) untuk data posttest adalah $0,000<0,05$ maka keputusan 
yang diperoleh adalah tolak HO yang berarti data berbeda signifikan. Ini artinya siswa pada kelas kontrol dan kelas eksperimen memiliki penguasaan konsep yang berbeda pada materi sistem ekskresi.

Berikut merupakan hasil $N$-gain pada kelas kontrol dan eksperimen sebagai berikut :

Tabel 5 : Statistik Deskriptif Nilai $N$-Gain

\begin{tabular}{|c|c|c|c|c|c|c|}
\hline \multirow{2}{*}{ Kelas } & \multirow{2}{*}{$\mathbf{n}$} & \multicolumn{3}{|c|}{$N$-gain } & \multirow{2}{*}{} & \multirow{2}{*}{ Kategori } \\
\cline { 3 - 6 } & & $\begin{array}{c}\text { Nilai } \\
\text { Ideal }\end{array}$ & $\begin{array}{c}\text { Nilai } \\
\text { Min }\end{array}$ & $\begin{array}{c}\text { Nilai } \\
\text { Max }\end{array}$ & Rerata & Kategong \\
\hline Kontrol & 26 & 1.00 & 0.09 & 0.75 & 0.31 & Sedang \\
\hline Eksperimen & 26 & 1.00 & 0.20 & 0.75 & 0.57 & Sedang \\
\hline
\end{tabular}

Berdasarkan Tabel 5 terlihat bahwa nilai rerata $N$-Gain kelas kontrol 0.31 dan kelas eksperimen 0.57 . Minimum pada kelas kontrol adalah 0.09 sedangkan pada kelas eksperimen 0.20 nilai maksimum pada kelas kontrol adalah 0.75 sedangkan pada kelas eksperimen nilai maksimum adalah 0.75 . Rerata $N$-Gain kelas eksperimen lebih tinggi dibandingkan rerata

$N$-Gain kelas kontrol. Rerata $N$-Gain untuk kelas eksperimen adalah 0.57 kategori sedang dan rerata $N$-Gain kelas kontrol adalah 0.31 kategori sedang. Berikut diagram batang rerata $\mathrm{N}$-Gain kelas kontrol dan kelas eksperimen.

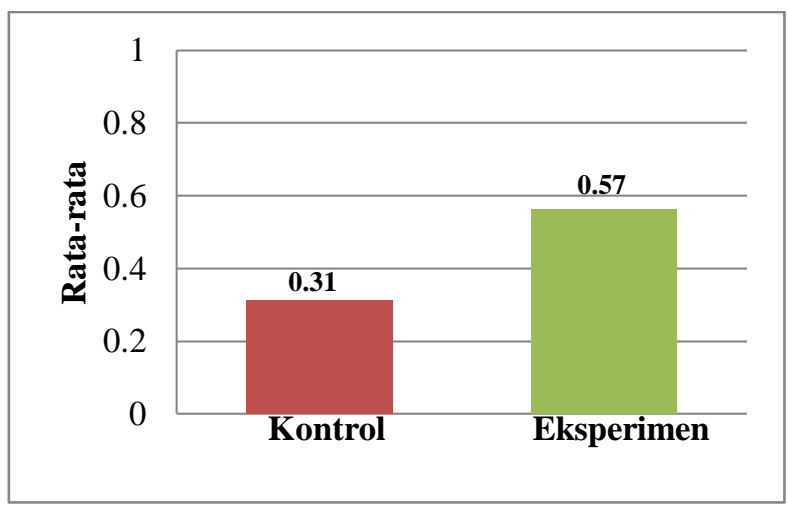

Gambar 1. Diagram batang N-Gain

Data $N$-gain kelas kontrol dan kelas eksperimen kemudian dianalisis dengan melakukan uji normalitas, uji homogenitas dan uji-t. Hasil uji-t data $N$-gain dapat dilihat pada Tabel 6.

Tabel 6 : Rekapitulasi Hasil Uji-t $N$-Gain

\begin{tabular}{|c|c|c|c|c|}
\hline $\begin{array}{l}\text { Jenis } \\
\text { Data }\end{array}$ & $\begin{array}{l}\text { Asimp. } \\
\text { Sig(2- } \\
\text { tailed) }\end{array}$ & $A$ & $\begin{array}{c}\text { Keputusa } \\
\text { n }\end{array}$ & Keterangan \\
\hline $\begin{array}{c}N- \\
\text { Gain }\end{array}$ & 0.000 & 0.05 & Tolak $\mathrm{H}_{0}$ & $\begin{array}{c}\text { Berbeda } \\
\text { signifikan }\end{array}$ \\
\hline
\end{tabular}

Tabel 6 dapat dilihat hasil uji-t untuk data $N$-gain kelas kontrol dan kelas eksperimen dengan $\alpha=0.05$ diperoleh nilai Sig (2-tailed) 0.000 dari hasil tersebut keputusan yang diperoleh adalah tolak $\mathrm{H}_{0}$ yang artinya data berbeda signifikan, karena nilai Sig (2tailed) $0.000<0.05$ hal ini menunjukkan bahwa siswa pada kelas kontrol dan kelas eksperimen mempunyai perbedaan penguasaan konsep pada materi sistem eksresi pada 
manusia. Berikut Diagram garidan kelas eksperimen pada materi sistem eksresi perbandingan $\mathrm{N}$-Gain persiswa pada manusia mempunyai pengetahuan awal kelas kontrol dan kelas eksperimen sama. Hal tersebut dikarenakan dari kedua kelas

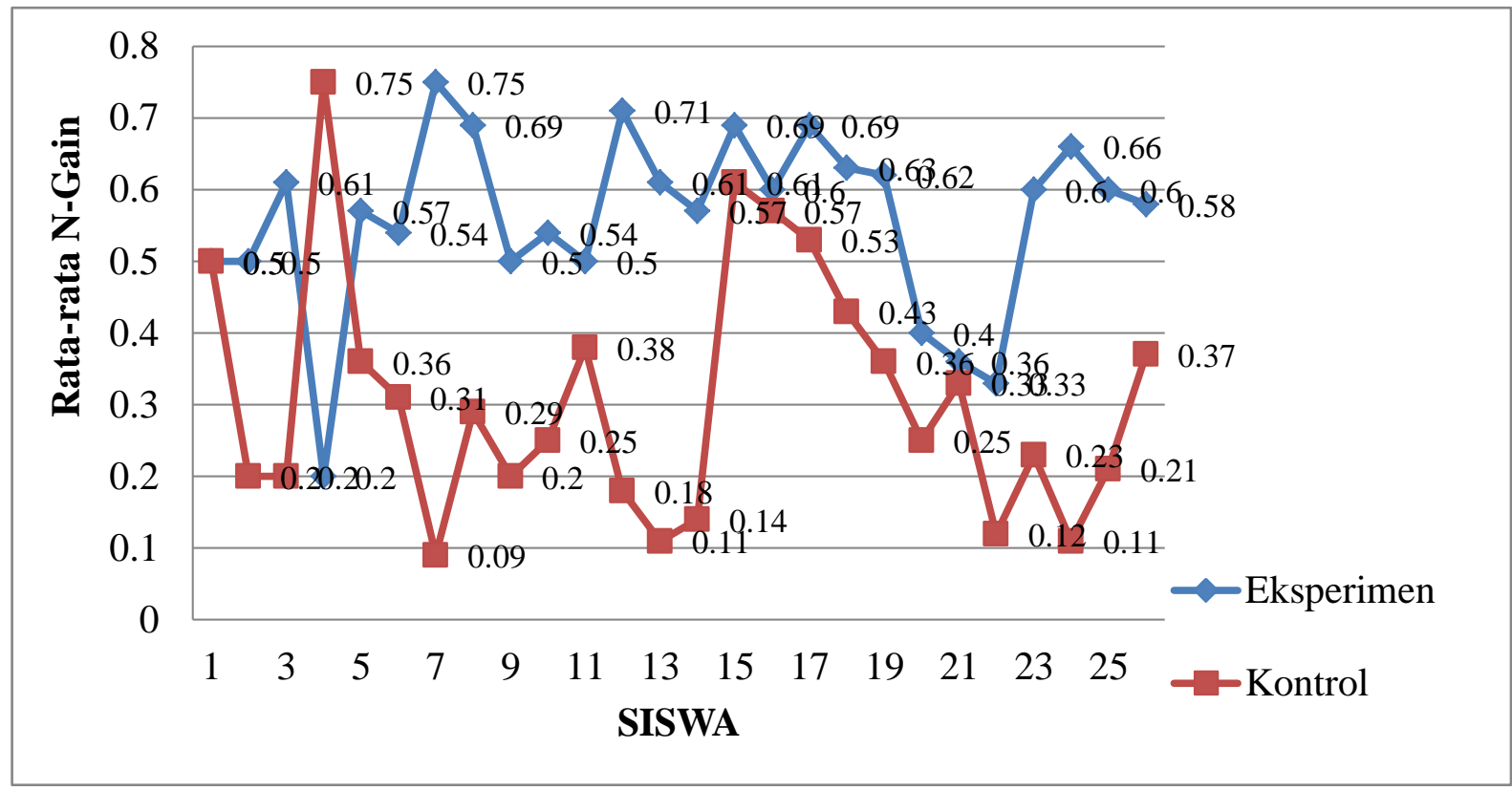

Gambar 2. Diagram garis perbandingan $N$-Gain tersebut masing-masing belum mendapat

Hasil $N$-gain menunjukkan terjadinya pengaruh signifikan terhadap penguasaan konsep siswa pada materi sistem eksresi pada manusia, hasil yang didapat antara kelas kontrol dan kelas eksperimen memiliki perbedaan penguasaan konsep pada materi sistem eksresi pada manusia.

Nilai $N$-gain kelas eksperimen yang menggunakan pembelajaran metode mind mapping dan habits of mind lebih tinggi dibandingkan dengan kelas kontrol yang menggunakan pembelajaran konvensional.

\section{PEMBAHASAN}

Berdasarkan hasil analisis data pretest yang telah diuji dengan menggunakan Uji-t menunjukkan bahwa siswa pada kelas kontrol

perlakuan dalam proses pembelajaran sistem eksresi. Hal ini sesuai dengan salah satu karateristik penelitian eksperimen yang dikemukakan oleh (Hamalik, 2001).

Belajar adalah suatu proses perubahan tingkah laku individu melalui interaksi dengan lingkungan. Belajar bukanlah suatu tujuan, namun belajar adalah suatu proses untuk mencapai tujuan. Hal ini sejalan dengan (Hamdani, 2010). Proses pembelajaran merupakan proses komunikasi antara guru dan siswa.

Proses Pembelajaran merupakan suatu proses yang mengandung 
serangkaian perbuatan guru dan siswa atas hubungan timbal balik yang berlangsung dalam situasi edukatif untuk mencapai tujuan tertentu, dimana dalam proses tersebut terkandung multi peran dari guru. Peran guru meliputi banyak hal, yaitu guru dapat berperan sebagai pengajar, pemimpin kelas, pembimbing, pengatur lingkungan belajar, perencana pembelajaran, supervisor, motivator, dan sebagai evaluator (Rusman, 2013).

Setelah dilakukan proses pembelajaran dengan menerapkan metode mind mapping dan habits of mind di kelas eksperimen dan

di kelas kontrol menggunakan pembelajaran konvensional dengan metode ceramah di kelas kontrol, dilakukan analisis data posttest yang menggunakan uji-t menunjukkan bahwa terdapat perbedaan yang signifikan hasil penguasaan konsep siswa antara kelas kontrol maupun kelas eksperimen pada materi sistem ekskresi,

Analisis $N$-gain menunjukkan terjadinya perbedaan penguasaan konsep pada materi sistem eksresi pada manusia kelas eksperimen yaitu 0.57 sedangkan kelas kontrol 0.31. Rerata $N$-gain kelas eksperimen dikategorikan sedang, sedangkan kelas kontrol dikategorikan sedang. Walaupun demikian dapat diambil kesimpulan

bahwa penguasaan konsep siswa kelas eksperimen lebih tinggi dibandingkan pada kelas kontrol.

Secara keseluruhan penggunaan pembelajaran metode mind mapping berpengaruh positif terhadap proses pembelajaran karena selain membantu membuat siswa aktif juga dapat meningkatkan

penguasaan konsep pada materi sistem eksresi manusia yang menerapkan metode mind mapping. Didukung oleh pendapat (Rosser \& Hamdani e.t al, 2012) menyatakan bahwa konsep merupakan buah pemikiran seseorang atau sekelompok orang yang dinyatakan dalam defenisi. Hail ini juga sejalan dengan pendapat (Anderson \& Krathwohl, 2010) menyatakan bahwa ranah kognitif menyatakan kembali prinsip yang telah dipelajari serta kemampuan intelektualnya.

Peningkatan penguasaan konsep siswa juga dipengaruhi oleh aktifitas siswa dan guru dilihat dari lembar observasi aktifitas siswa dan guru. Dari hasil penelitian yang telah dilakukan diperoleh rerata aktifitas siswa pada kelas kontrol pertemuan pertama $58,65 \%$ dan pertemuan kedua $74,03 \%$.

Bio-Lectura: Jurnal Pendidikan Biologi, Vol 6, No 2, Oktober 2019 
Sedangkan hasil observasi di kelas eksperimen pada pertemuan pertama terlihat bahwa rerata persentase Hasil aktifitas guru di kelas kontrol, rerata persentase pertemuan pertamanya $100 \%$ dan persentase pertemuan kedua $100 \%$ aktifitas guru telah dilakukan sebaik mungkin baik kelas kontrol maupun kelas eksperimen.

\section{KESIMPULAN}

Berdasarkan hasil penelitian dan analisis data yang dilakukan dapat disimpulkan bahwa penggunaan metode mind mapping bepengaruh 3 signifikan terhadap penguasaan konsep siswa pada materi Sistem Eksresi Manusia dikelas VIII SMP Negeri 33 Pekanbaru Tahun Ajaran 2018/2019. Hasil $N$-gain, pada kelas eksperimen yaitu 0.57 dengan kategorikan sedang sedangkan kelas kontrol 0.31 dikategorikan sedang. Selain dapat meningkatkan penguasaan konsep siswa, metode mind mapping juga dapat meningkatkan aktivitas belajar siswa dan aktivitas guru dalam proses belajar mengajar.

\section{SARAN}

Mengingat hasil penelitian maka yang dapat disampaikan yaitu

1. Kepada guru agar dapat menggunakan metode pembelajaran pertemuan pertama $90,38 \%$ dan rerata persentase pertemuan kedua meningkat menjadi $96,15 \%$.

metode mind mapping sebagai variasi metode dalam pembelajaran biologi sehingga dapat meningkatkan penguasaan konsep siswa, meningkatkan aktivitas siswa dan menumbuhkan semangat belajar siswa, khususnya pada materi sistem eksresi.

2. $\quad$ Metode mind mapping bisa juga digunakan pada materi biologi yang lainnya. Bagi peneliti selanjutnya agar bisa menggunakan.

\section{DAFTAR PUSTAKA}

Anderson W., L, \& Krathwol, R., D. 2010. Pembelajaran pengajaran dan assasmen, Pustaka pelajar: Yogyakarta.

Arikunto S. 2011. Dasar-dasar evaluasi pendidikan. Bumi aksara: Jakarta.

Buzan T. 2006. Buku pintar mind map untuk anak agar pintar disekolah. Jakarta: Gramedia Pusaka Utama.

Costa A. L. \& Kallick, B. 2009. Learning and Leading with Habits ofMind:16EssentialCharacteristics for success. Universitas Pendidikan Indonesia Bandung.

Dahar. 2006. Pengertian Konsep dan Memecahkan masalah. Bumi aksara: Jakarta. 
Dimyati \& Mudjiono. 2002. Belajar dan Pembelajaran. Rineka Cipta: Jakarta.

Faidah R, \& Nurul, U. 2009. Buku Biologi Untuk SMA kelas XI. Ricardo,C: Jakarta.

Hamalik, Oemar. 2001. Proses Belajar Mengajar. Bumi Aksara : Bandung.

Hamalik, O. 2009. Proses Belajar Mengajar. Bumi Aksara: Jakarta.

Hamdani. 2010. Strategi Belajar Mengajar. Pustaka Setia : Bandung.

Hamdani D., Kurniati, E., \& Sakti, I. 2012. Pengaruh Model Pembelajaran Generatif dengan Menggunakan Alat Peraga Terhadap Pemahaman Konsep Cahaya Kelas VIII SMPN 7 Kota Bengkulu. Jurnal Exacta. Vol 10. No 1.

Jensen, E, \& Markowitz .2002. Mind Mapping. Pustaka Belajar : Yogyakarta

Lestari, S.,E, \& Kristinnah, I.2009. Buku Biologi Untuk SMA kelas XI dan Lingkungannya. Putra Nugraha: Jakarta.

Marita., S.A.R,. Rahman, T, Surakusumah, W.2014. Potensi Habits Of Mind Siswa Pada konsep sistem organ menggunakan metode pratikum dan diskusi. Universitas Pendidikan Indonesia : Bandung

Marzono. 1992. Dimensi Belajar Mengajar. Bumi Aksara: Jakarta.
Mc. Milan \& Schumacher.2001. Penelitian kuasi experimen Control Group Pretest Posstest Design.

Meltzer, D.E.2002. "The Reletionsip between Matematics Preparation and Conceptual Learning Gains in physicn:A possible "hidden variable" in diagnostic pretest scores". American journal of physics. Vol 70 No 12.

Prasetyo, Faisal Imam. 2012. Pengaruh Penerapan Quantum Learning Terhadap Hasil Belajar Biologi Siswa Kelas X SMA Negeri 4 Surakarta Tahun Pelajaran 2011/2012. Universitas Sebelas Maret : Surakarta.

Rachmawati, N., S., Widayati S, \& Arif P., M.2009. Buku Biologi Untuk SMA/MA kelas XI. Pustaka Ihsan Madani: Jakarta.

Ratnasari, Y.2010. Penerapan strategi SQ3R dan peta konsep dalam pembelajaran fisika ditinjau dari kreativitas siswa. Jurnal pendidikan MIPA. Vol 2. No 1.

Roger \& Johnson. 2013. Model model media dan strategi pembelajaran kontekstual (inovatif). Yrama Widya: Bandung.

Rusman.2013.BelajardanPembelajara $n$ Berbasis Komputer.Alfabeta : Bandung.

Sasmita,. D., Ningsih,. K, Wahyuni, S.K,2015. Pengaruh strategi quantum learning teknik mind 
mapping terhadap hasil belajar siswa materi sistem eksresi kelas VIII SMP Negeri 3 Sungai Raya Tahun Ajaran 2015/2016. Universitas Sebelas Maret : Surakarta.

Saleh, A.2009. Kreatif Mengajar dengan Mind Map. Tinta Emas Publishing : Bandung.

Slavin, R.,E. 2005. Cooperative learning. Nusa Media: Bandung.

Sriyati, S. 2011. Penerapan Asesmen Formatif Untuk Membentuk Habits Of Mind Mahasiswa Biologi. Sekolah Pascasarjana UPI. Disertasi. Tidak diterbitkan.

Steinkuehler, C. \& Duncan, S. 2008. Scientific habits of mind in virtual worlds. J Sci Educ Technol. 17, hlm. 530-543.

Tersediadihttp://download.springer.co $\mathrm{m} / \mathrm{static} / \mathrm{pdf} / 479 /$ art\%253A10.1007\%2 52Fs1095600891208.pdf?auth66=1419 397992_aaefbc2f359a2cb7246ea42d20 56f8ed\&ext=.pdf. Diakses 21 April 2014.

Suardiantini,P, \& Nita.2014. Pengaruh Penerapan Model Pembeajaran Inkuiri Terbimbing (Guided Inquiry) Divariasikan Dengan Media Mind Mapping Terhadap Minat Belajar Biologi Siswa Kelas VII SMP PGRI 4 Denpasar Tahun Ajaran 2013/2014. Skripsi, Program Studi Pendidikan Biologi Fakultas Keguruan Dan Ilmu Pendidikan Universitas Mahasaraswati Denpasar.
Sugihartono.2007.Metode Habits Of Mind upaya kemampuan anak menyelesaikan masalah dalam dunia nyata. Pusaka Utama: Jakarta.

Sugiyono. 2007. Statistik.Gadjah Mada Press: Yogyakarta.

Sugiyono. 2010. Statistik untuk Penelitian. Alfabeta: Bandung.

Suprijono, A. 2013. Cooperative learning. Pustaka Pelajar: Yogyakarta. Trianto, 2012. Model pembelajaran terpadu. Bumi aksara: Jakarta.

Wulandari,A.2010. Metode Penelitian Tersediahttp;//www.Trinoval.Web. $\underline{\mathrm{Id} / 2010 / 04 / j e n i s}$ uji statistik. [16 Januari 2014]. 